\title{
OCEANOGRAFIA E QUÍMICA: UNINDO CONHECIMENTOS EM PROL DOS OCEANOS E DA SOCIEDADE
}

Vanessa Hatje*

Instituto de Química, Universidade Federal da Bahia, Salvador - BA, Brasil

Mônica Ferreira da Costa

Departamento de Oceanografia, Universidade de Pernambuco, Recife - PE, Brasil

Letícia Cotrim da Cunha

Departamento de Oceanografia Química, Faculdade de Oceanografia, Universidade do Estado do Rio de Janeiro, Rio de Janeiro - RJ, Brasil

Recebido em 17/7/13; aceito em 2/9/13; publicado na web em 18/9/13

\begin{abstract}
OCEANOGRAPHY AND CHEMISTRY: BRIDGING KNOWLEDGE IN FAVOR OF THE OCEANS AND SOCIETY. The marine environment is certainly one of the most complex systems to study, not only because of the challenges posed by the nature of the waters, but especially due to the interactions of physical, chemical and biological processes that control the cycles of the elements. Together with analytical chemists, oceanographers have been making a great effort in the advancement of knowledge of the distribution patterns of trace elements and processes that determine their biogeochemical cycles and influences on the climate of the planet. The international academic community is now in prime position to perform the first study on a global scale for observation of trace elements and their isotopes in the marine environment (GEOTRACES) and to evaluate the effects of major global changes associated with the influences of megacities distributed around the globe. This action can only be performed due to the development of highly sensitive detection methods and the use of clean sampling and handling techniques, together with a joint international program working toward the clear objective of expanding the frontiers of the biogeochemistry of the oceans and related topics, including climate change issues and ocean acidification associated with alterations in the carbon cycle. It is expected that the oceanographic data produced this coming decade will allow a better understanding of biogeochemical cycles, and especially the assessment of changes in trace elements and contaminants in the oceans due to anthropogenic influences, as well as its effects on ecosystems and climate. Computational models are to be constructed to simulate the conditions and processes of the modern oceans and to allow predictions. The environmental changes arising from human activity since the $18^{\text {th }}$ century (also called the Anthropocene) have made the Earth System even more complex. Anthropogenic activities have altered both terrestrial and marine ecosystems, and the legacy of these impacts in the oceans include: $a$ ) pollution of the marine environment by solid waste, including plastics; $b$ ) pollution by chemical and medical (including those for veterinary use) substances such as hormones, antibiotics, legal and illegal drugs, leading to possible endocrine disruption of marine organisms; and c) ocean acidification, the collateral effect of anthropogenic emissions of $\mathrm{CO}_{2}$ into the atmosphere, irreversible in the human life time scale. Unfortunately, the anthropogenic alteration of the hydrosphere due to inputs of plastics, metal, hydrocarbons, contaminants of emerging concern and even with formerly "exotic" trace elements, such us rare earth elements is likely to accelerate in the near future. These emerging contaminants would likely soon present difficulties for studies in pristine environments. All this knowledge brings with it a great responsibility: helping to envisage viable adaptation and mitigation solutions to the problems identified. The greatest challenge faced by Brazil is currently to create a framework project to develop education, science and technology applied to oceanography and related areas. This framework would strengthen the present working groups and enhance capacity building, allowing a broader Brazilian participation in joint international actions and scientific programs. Recently, the establishment of the National Institutes of Science and Technology (INCTs) for marine science, and the creation of the National Institute of Oceanographic and Hydrological Research represent an exemplary start. However, the participation of the Brazilian academic community in the latest assaults on the frontier of chemical oceanography is extremely limited, largely due to: $i$. absence of physical infrastructure for the preparation and processing of field samples at ultra-trace level; $i i$. limited access to oceanographic cruises, due to the small number of Brazilian vessels and/or absence of "clean" laboratories on board; iii. restricted international cooperation; $i v$. limited analytical capacity of Brazilian institutions for the analysis of trace elements in seawater; $v$. high cost of ultrapure reagents associated with processing a large number of samples, and vi. lack of qualified technical staff. Advances in knowledge, analytic capabilities and the increasing availability of analytical resources available today offer favorable conditions for chemical oceanography to grow. The Brazilian academic community is maturing and willing to play a role in strengthening the marine science research programs by connecting them with educational and technological initiatives in order to preserve the oceans and to promote the development of society.
\end{abstract}

Keywords: Chemical Oceanography; anthropogenic impacts; scientific challenges.

\section{INTRODUÇÃO}

Dentre os grandes desafios da humanidade destacam-se a produção a e qualidade dos alimentos, a qualidade das águas continentais e oceânicas e a preservação dos ecossistemas frente ao cenário de

*e-mail: vhatje@gmail.com crescentes impactos antrópicos. A Oceanografia e a Química, juntas, desempenharão um papel de destaque nas reflexões e busca de soluções para subsidiar o desenvolvimento sustentável de uma sociedade justa, instruída e crítica que atue de forma ativa na busca de soluções para os desafios impostos pela humanidade.

Este manuscrito, no escopo deste Número Especial Química sem Fronteiras, e em aderência com as ações previstas pela Sociedade 
Brasileira de Química como contribuição ao Fórum Mundial de Ciências, ${ }^{1}$ trará um balanço dos desenvolvimentos alcançados na Oceanografia Química nas últimas décadas e que permitiram hoje um melhor conhecimento da biogeoquímica das águas costeiras e oceânicas e suas interações com os processos biológicos que entre outros, atuam no controle do clima. Obviamente, estes avanços também permitiram a identificação de uma série de mazelas associadas ao desenvolvimento desordenado das megacidades e ao descaso da sociedade com os ecossistemas costeiros. Os desafios do futuro são muitos e vão requerer uma ação concertada na área de ensino, pesquisa e inovação tecnológica para garantir um futuro próspero para o planeta.

O planeta Terra é visto como um mundo biologicamente abundante. Entretanto, quase três quartos do planeta são cobertos por água, e quase metade desta superfície é coberta por regiões oceânicas onde a vida é relativamente rara. Estes ecossistemas esparsamente habitados são ricos em água, luz, hidrogênio, oxigênio e carbono, que são os principais componentes para a proliferação da vida. Mas estas áreas são deficientes em um ou mais elementos que, mesmo em concentrações extremamente baixas, são necessários para a manutenção da vida. Portanto, a distribuição da biota nos oceanos é, pelo menos em parte, cativa da distribuição de cerca de vinte elementos químicos que são componentes fundamentais do DNA, RNA, enzimas e outras moléculas biológicas. ${ }^{2}$

Desde a sua origem, há cerca de quatro bilhões de anos atrás, a salinidade dos oceanos (Figura 1), determinada principalmente por cloretos, manteve-se em um intervalo tolerável para o aparecimento e a prosperidade das mais diversas formas de vida, enquanto as concentrações de oxigênio livre, nitrogênio, sulfato, sulfeto, ferro dissolvido e carbonato-bicarbonato variaram consideravelmente..$^{3,4}$ Mudanças na química dos oceanos ao longo do tempo geológico causaram variações substanciais na estequiometria dos elementos traço na água do mar, assim como em seus estados de oxidação. Dentre estes elementos, cabe destacar os metais de transição, como o manganês, o cobalto, o níquel, o cobre e o zinco, que são sensíveis a mudanças redox. Processos de oxirredução e outras alterações na composição química dos oceanos afetaram a biosfera e a evolução da vida nos diversos ambientes marinhos. ${ }^{5}$

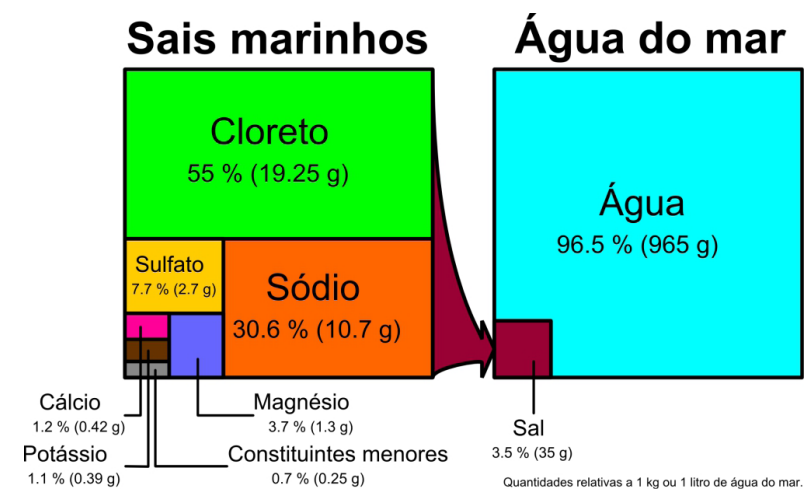

Figura 1. Constituição média da água do mar de salinidade 35

O oceano moderno é constantemente misturado pela circulação termohalina em ciclos de 500-1000 anos. ${ }^{6} \mathrm{~A}$ circulação promove, dentre muitos outros fenômenos oceanográficos, como a transferência de calor na interface oceano - atmosfera, uma distribuição relativamente eficiente do oxigênio dissolvido $\left(\mathrm{O}_{2}\right)$ nos oceanos, mantendo as águas, em grande parte, em condições óxicas. Consequentemente, muitos elementos traço nos oceanos ocorrem em seu maior estado de oxidação, sendo hidrolisados ou formando espécies com oxigênio. Além disso, diversos compostos orgânicos presentes nas massas d'água oceânicas, particulados e dissolvidos, propiciam a complexação de muitos elementos traço.

O desenvolvimento e aplicação de métodos de detecção altamente sensíveis, associados a métodos de amostragem empregando técnicas "limpas", desde a década de 1970, permitiram a determinação de padrões verticais de distribuições oceanograficamente consistentes para muitos elementos traço. ${ }^{7-9}$ Os perfis tipo nutriente são exemplos de padrões consistentes na distribuição de elementos traço, como o cádmio e o zinco, e indicam que estes elementos são consumidos na superfície e regenerados na coluna d'água, com a decomposição da matéria biogênica. ${ }^{10,11}$

Há, hoje, perfis verticais para a grande maioria dos elementos da tabela periódica, assim como para muitos dos seus isótopos estáveis e radioativos. ${ }^{12,13}$ Os espectrômetros de massa com fonte de plasma e multi coletores (MC-ICP-MS) permitem hoje o estudo sistemático de fracionamento isotópico - um campo bastante novo de pesquisa na oceanografia química.

Uma vez vencidos os desafios associados aos procedimentos limpos de coleta e análise de elementos presentes na água do mar em concentrações nano e/ou pico molar, a importância e o papel de tais elementos como micronutrientes e suas implicações para a produção primária dos oceanos puderam então ser melhor compreendidos. Os conhecimentos acerca da ciclagem biogeoquímica destes elementos têm efeitos diretos em diversas áreas de pesquisa, como o ciclo do carbono, mudanças climáticas, ecologia, produtos naturais e contaminação ambiental. Pesquisas sobre o Fe, por exemplo, mostraram que este não é apenas um micronutriente essencial para o fitoplâncton marinho, mas também que concentrações extremamente baixas deste elemento limitam a produtividade de cerca de $30 \%$ dos produtores primários dos oceanos. ${ }^{14}$ Desde então, autores têm discutido como incrementos nos aportes de Fe para os oceanos podem vir a subsidiar o aumento da produtividade primária, de modo a promover o sequestro de carbono e a diminuição dos teores de $\mathrm{CO}_{2}$ atmosféricos, ${ }^{15,16}$ inaugurando uma era de tentativas de engenharia planetária, que mais tarde incluiu o bombeamento de $\mathrm{CO}_{2}$ para o fundo dos oceanos.

Apenas a partir dos anos 1990 é que a variedade de papéis que cada elemento exerce na estrutura e funcionamento dos ecossistemas começou a ser revelada. ${ }^{17,18}$ Entretanto, a significância de cada elemento químico e seu ciclo biogeoquímico nos oceanos apenas muito recentemente começou a ser entendida, ${ }^{19,20}$ graças a esforços de grandes programas de pesquisa internacionais. O Estudo Seções Geoquímicas dos Oceanos (GEOSECS), desenvolvido nos anos 1970, promoveu a primeira visão global da distribuição de muitas espécies dissolvidas. Este conhecimento conduziu ao avanço no entendimento da circulação dos oceanos e ciclos biogeoquímicos, particularmente com o uso de isótopos como ${ }^{14} \mathrm{C},{ }^{210} \mathrm{~Pb},{ }^{226} \mathrm{Ra}$ para a determinação de taxas de diversos processos internos nos oceanos. ${ }^{21}$ Paralelamente, elementos traço e seus isótopos têm sido usados para o desenvolvimento de novos proxies para aplicação em paleoceanografia, ${ }^{22}$ por meio do estudo da composição de sedimentos, corais e fósseis. ${ }^{23} \mathrm{~A}$ razão $\mathrm{Cd} / \mathrm{Ca}$, por exemplo, pode ser usada como análoga da concentração de fosfato no paleooceano, a razão $\mathrm{Mg} / \mathrm{Ca}$ pode ser interpretada como proxies de paleotemperaturas, ${ }^{24}$ enquanto a razão $\mathrm{B} / \mathrm{Ca}$ tem sido empregada para reconstruir mudanças no ciclo do $\mathrm{CO}_{2}$ e sistema carbonato-bicarbonato no paleooceano. ${ }^{25}$

Entretanto, apesar de todos os avanços nos últimos 40 anos desde o GEOSECS e vários esforços internacionais como o Programa Elementos de Transição nos Oceanos (TTO) e o Programa Experimento de Circulação do Oceano Mundial (WOCE), ainda não foi atingida uma posição satisfatória frente à distribuição tridimensional dos elementos traço nos oceanos e, principalmente, seus fluxos nas interfaces oceano-continente-atmosfera e sobre seus impactos no clima. Diante deste panorama, a habilidade de realizar simulações 
de cenários que produzam resultados maduros e robustos para testar modelos e fazer previsões sobre os mais diversos processos nos oceanos modernos, a exemplo da acidificação dos oceanos, ainda encontra-se longe do desejável.

Atualmente, o Estudo Internacional dos Ciclos Biogeoquímicos dos Elementos Traço e seus Isótopos (GEOTRACES) procura avançar e sanar muitas das lacunas previamente levantadas. Este é, possivelmente, o maior dos esforços até o presente para avaliar fontes, sumidouros e a ciclagem interna de elementos traço e seus isótopos. Este projeto objetiva, entre outros, entender o ciclo dos elementos traço suficientemente bem para avaliar a resposta destes ciclos as mudanças globais hoje previstas, assim como o impacto no ciclo do carbono e no clima. ${ }^{26}$

Existem numerosas evidências de que a produção primária e os ciclos biogeoquímicos dos oceanos são importantes fatores na manutenção e controle do clima no planeta. ${ }^{27}$ Processos biológicos influenciam a abundancia de $\mathrm{CO}_{2},{ }^{28} \mathrm{NO}_{2},{ }^{29}$ dimetilsulfato e aerossóis, ${ }^{30,31}$ que são importantes agentes na regulação do clima e na intensidade do efeito estufa. Não há dúvida que os elementos químicos, individualmente ou em conjunto, atuam de maneira significativa em organismos e na própria estrutura dos ecossistemas oceânicos, os quais são fatores chave para regulagem do ciclo do carbono em todo o planeta, visto que são afetados e influenciam as mudanças globais.

Sendo assim, a química e a física dos oceanos regem não só variações climáticas de médio e longo prazos, mas também a disponibilidade de recursos vivos e não vivos.

\section{RUMO ÀS MEGACIDADES DO SÉCULO XXI}

A determinação da maioria das formas dos elementos químicos nos oceanos ainda é um desafio oceanográfico e analítico, grande parte devido às concentrações baixas nas quais os elementos se encontram. Por outro lado, nas águas costeiras ou continentais as concentrações dos elementos são, em geral, significativamente maiores devido a fenômenos naturais de intemperismo continental, mistura vertical e ressuspensão de sedimentos, e as diversas formas de influência antrópica. Sendo assim, em águas estuarinas e costeiras sua determinação é facilitada e a compreensão de seu comportamento vem crescendo mais rapidamente.

Os problemas associados às ações desenvolvidas pelo homem, incluindo a contaminação das águas, não são recentes. Estes surgiram há muito tempo, quando vários grupos de pessoas se estabeleceram permanentemente em uma dada área, criando as primeiras vilas e cidades. Com o progresso da tecnologia, a domesticação de animais e intensificação das práticas agrícolas, a carga de resíduos produzida começou a ser aumentada e a partir deste período a contaminação do ambiente começou a existir. ${ }^{32}$ A extensão do problema certamente aumentou proporcionalmente ao crescimento das cidades.

Nos últimos 300 anos a população mundial aumentou dez vezes, atingindo mais de sete bilhões de habitantes. ${ }^{33}$ Com o aumento da população houve o crescimento per capita do uso de energia, da exploração dos recursos naturais e produção de resíduos sólidos e efluentes líquidos. A Revolução Industrial, por sua vez, contribuiu não apenas para o incremento de usos de recursos naturais e migração de áreas rurais para as zonas urbanas, mas também para a deterioração da qualidade do ambiente devido à invenção das máquinas movidas a carvão e o aumento na produção e emissão de contaminantes.

Esta era de grandes mudanças nos ecossistemas causadas pela sociedade moderna pode ser chamada de Antropoceno. ${ }^{34}$ Segundo Crutzen, ${ }^{34}$ este período teria começado no século XVIII, quando acelerou-se a taxa de crescimento das concentrações atmosféricas de dióxido de carbono e metano. Recentemente, a concentração de $\mathrm{CO}_{2}$ na atmosfera superou a marca de $400 \mathrm{ppm}$ pela primeira vez desde o
Plioceno (5-3 milhões de anos atrás) ${ }^{35}$ Cabe lembrar que as mudanças observadas hoje em termos de concentração de $\mathrm{CO}_{2}$ na atmosfera são mais rápidas e bastante superiores àquelas vivenciadas nos últimos períodos glaciais e interglaciais, ${ }^{36}$ o que indica que, provavelmente, foram aceleradas pelo homem (Figura 2).

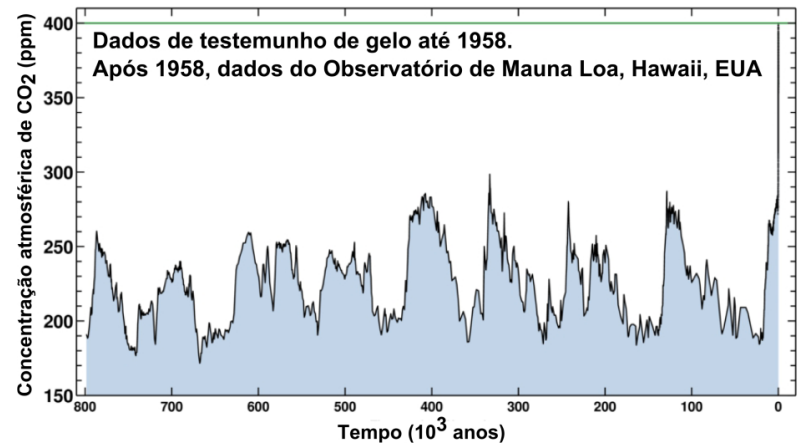

Figura 2. Variação da concentração atmosférica de $\mathrm{CO}_{2}$ em ppm ao longo do tempo (800 ka até o presente) medida em testemunhos de gelo e diretamente da atmosfera (a partir de 1958). Gráfico modificado do Instituto Oceanográfico Scripps, EUA ${ }^{35}$

Hoje, mais da metade da população mundial vive em cidades e muitos dos habitantes estão concentrados nas chamadas megacidades com mais de 10 milhões de habitantes. ${ }^{37}$ Dentre as atuais 23 megacidades, 15 (Shenzhen, Guangzhou, Lagos, Istambul, Osaka-Kobe, Manila, Kolkata, Dhaka, Tokyo, Rio de Janeiro, New York, Mumbai, Karachi, Buenos Aires e Los Angeles) estão localizadas em estuários ou na zona costeira. Existe expectativa que estes números aumentem, consequentemente impondo mais pressão nos recursos naturais devidos às múltiplas e potencialmente conflitantes atividades antrópicas. A concentração populacional em torno dos recursos hídricos e o lançamento pontual de seus rejeitos fazem parte das chamadas síndromes dos rios ${ }^{38}$ e síndromes costeiras. ${ }^{39}$ Alguns dos sintomas destas síndromes, como por exemplo, a hipoxia em zonas costeiras e as descargas de grandes quantidades de águas pluviais que carregam altas concentrações de contaminantes, são típicos das megacidades, sobretudo aquelas em regiões não assistidas por saneamento básico.

Paralelamente, nos últimos 20 anos houve um aumento das medidas reguladoras de produção e disposição de efluentes sólidos e líquidos. Estas medidas, entretanto, não foram suficientemente eficazes para conter a produção e/ou emissão de contaminantes para os corpos d'água, solos e atmosfera. Enquanto o controle de emissões via fontes pontuais foi dramaticamente reduzido, as águas de escoamento superficial, águas subterrâneas e atmosfera continuam transportando e adicionando contaminantes orgânicos e inorgânicos oriundos dos ambientes continentais para os oceanos.

No que concerne o desenvolvimento de novas tecnologias e materiais, é sabido que existe um enorme potencial em geração e/ou utilização de novos produtos químicos de toxicidade desconhecida. Alquilfenóis polietoxilados (APE), ftalatos, retardantes de chamas bromados (BFR), dioxinas, furanos, produtos de cuidado pessoal e fármacos são apenas alguns exemplos destes produtos, sendo que muitos destes são hoje ubíquos no ambiente. ${ }^{40-42}$ Isto se deve, em parte, à relativa ineficiência dos processos convencionais de tratamento de água e esgoto na remoção completa destes compostos de efluentes ${ }^{43}$ Especificamente, este é o caso do gadolínio (Gd), utilizado em aplicações biomédicas, como agente de contraste em exames de ressonância magnética e um excelente traçador da contaminação causada pelas megacidades nos sistemas aquáticos. ${ }^{44}$ Esse é também o caso de alguns compostos orgânicos de uso intenso nas sociedades de todo o mundo como a cafeína e a cocaína e seus derivados. 
Durante os últimos 20 anos, houve uma explosão não apenas no uso de Gd, mas também de outros elementos terras raras (REE). Os REE são um grupo de metais de importância estratégica para o desenvolvimento de novas tecnologias, como turbinas eólicas, motores elétricos de veículos, refino de petróleo e diagnósticos médicos. Hoje, estes elementos são utilizados em memórias de computador, DVD, baterias recarregáveis, telefones celulares, conversores catalíticos, magnetos, atividades militares, lâmpadas fluorescentes, entre outros.

Concentrações anômalas de Gd causadas por aportes antrópicos foram registradas pela primeira vez em rios na Alemanha. ${ }^{45}$ Desde então, vários estudos reportaram a presença de grandes anomalias de Gd em águas naturais, principalmente continentais, na Europa, América do Norte e Austrália. ${ }^{46}$ Recentemente, também foi documentado o primeiro caso de La e Sm em águas do rio Reno. ${ }^{46}$ Estes achados marcam o início de uma nova era na geoquímica dos REE, onde as atividades antrópicas potencialmente afetam a distribuição destes elementos em águas continentais e oceânicas.

A boa qualidade das águas, ou a ausência desta, é tão importante que a questão contaminação é considerada e/ou tem potencial impacto na maioria dos 10 indicadores do índice da saúde e benefícios dos oceanos proposto por Halpern e colaboradores. ${ }^{47}$ A composição da água do mar, tanto em termos de elementos traço, atuando como micronutrientes reguladores da produção primária ou como indicadores de contaminação, tem efeito direto na biodiversidade, provisão de alimentos (pesca, maricultura e atividades de extrativismo), turismo e ciclo do carbono nos oceanos. O Brasil apresenta hoje o valor de 62 de acordo com o índice que varia de zero (valor mínimo de qualidade) a cem (valor máximo de qualidade) ${ }^{47}$ Este índice coloca o Brasil na trigésima quinta posição, atrás de países como o Chile, Namíbia e Suriname, e permite identificar quais são as áreas que precisam de mais atenção para que se obtenha uma melhor qualificação em termos da integridade da saúde dos oceanos. A poluição, assim como os estoques de carbono, são indicadores nos quais o Brasil deverá investir esforços para melhorar, pois visto as práticas de controle e mitigação de impactos antrópicos nas bacias de drenagem em operação na costa brasileira, a tendência deste índice, infelizmente, não é aumentar.

\section{O LEGADO}

As mudanças causadas pela sociedade moderna certamente alteraram a habitabilidade e qualidade dos ambientes. Frequentemente, as mudanças decorrentes do desenvolvimento socioeconômico foram tão profundas que deixaram um legado de longo prazo com potencial de alterar negativamente a vida, não apenas da fauna e da flora sob influência direta das megacidades, mas também nos oceanos.

\section{Plásticos e seus poluentes associados}

A poluição marinha por lixo gerado pela sociedade e suas consequências para os oceanos são atualmente não apenas tratados no âmbito das organizações supra-governamentais, ${ }^{48}$ mas se tornaram indicadores consolidados da interferência humana no ambiente marinho ${ }^{47}$ e têm destaque na literatura científica internacional ${ }^{49,50} \mathrm{e}$ nacional. ${ }^{51-53}$ Apesar de haver preocupações legítimas com a presença nos ecossistemas marinhos de todos os diferentes materiais sólidos e semi-sólidos gerados, usados e posteriormente inadequadamente descartados pela sociedade, a classe de poluentes mais estudada nesse caso são os plásticos (Figura 3). ${ }^{51,54}$ Incluem-se nesse grupo genérico dos plásticos todas as substancias sintéticas derivadas do petróleo, que são transformadas em objetos de inúmeras formas, utilidades e tamanhos através de moldagem e outros processos industriais. Esse grupo inclui plásticos, isopor, fibras sintéticas, borrachas, espumas, entre outros. ${ }^{55}$

A presença de itens plásticos em praias e nos oceanos de todo o mundo é uma preocupação típica do pós II Guerra Mundial e foi estudada desde a década de 1970. No Brasil, desde a década de $1990,{ }^{51}$ o lixo marinho tem sido investigado em relação às suas características de composição, ${ }^{56}$ tamanho, ${ }^{57-59}$ fonte mais provável,${ }^{60}$ incrustações biológicas, ${ }^{61}$ comportamento espaço-temporal ${ }^{51,62,63}$ e percepção das pessoas quanto ao fenômeno. Também foi levada em consideração a possível ação tóxica dos plásticos e substâncias a eles associadas para humanos ${ }^{64}$ e organismos marinhos. ${ }^{63,65,66}$ Houve estudos produzidos tanto em praias urbanas ${ }^{60,62}$ quanto rurais, ${ }^{57,67}$ assim como em ilhas. ${ }^{68,69}$ Todos esses estudos foram reconhecidos como uma contribuição importante das áreas de química (principalmente da química analítica)
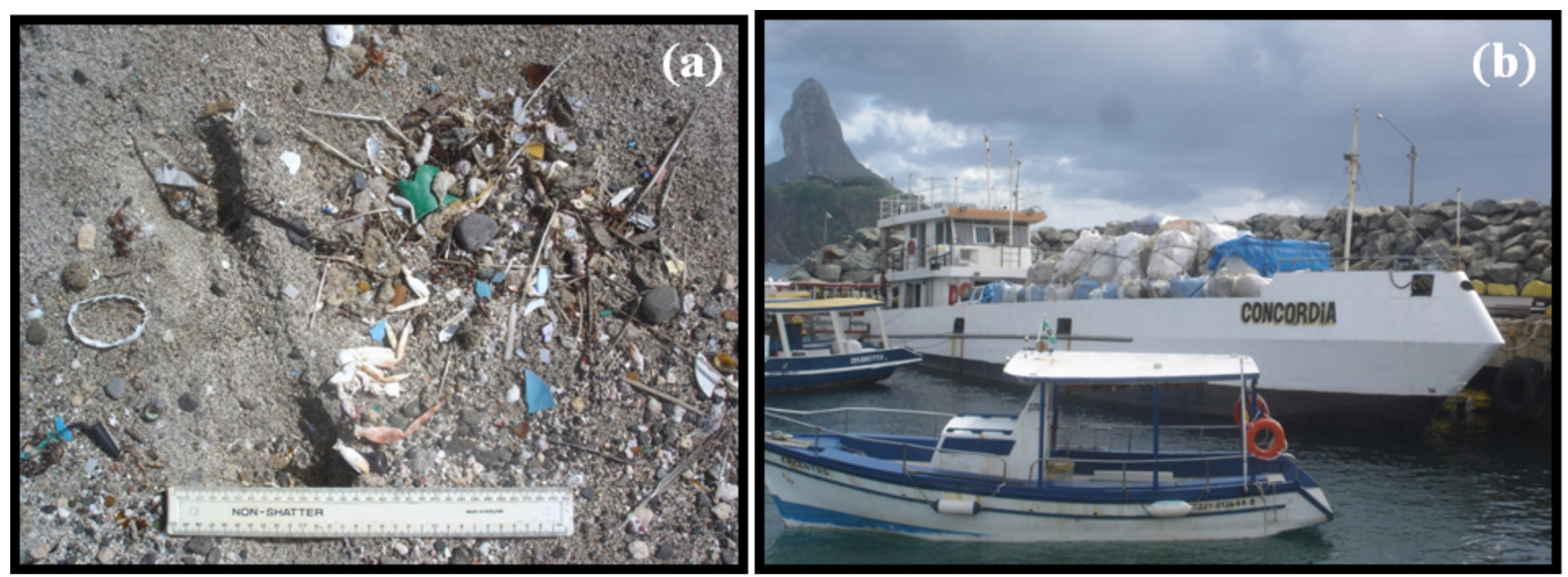

Figura 3. Mais de $8 \%$ da produção mundial de petróleo são destinados à produção de plásticos. Os plásticos são fundamentais na economia e sociedade, mas, eventualmente, eles são descartados. As escolhas feitas sobre o descarte dos plásticos podem levar à contaminação dos ecossistemas costeiros e marinhos. Químicos, Oceanógrafos e outros profissionais, inclusive das ciências sociais aplicadas, estudam em conjunto as interações dos plásticos com o meio ambiente e a biota, incluindo os processos de degradação e as melhores opções para sua redução e gestão. (a) Lixo marinho na praia do Atalaia em Fernando de Noronha tem origem marinha e local. O microlixo não pode ser removido do meio ambiente e permanece ali oferecendo risco à biota e às pessoas; (b) $o$ lixo produzido no arquipélago de Fernando de Noronha precisa ser removido periodicamente por um navio que o traz para destinação no continente. Fotos: Monica Ferreira da Costa e Ângela Spengler 
e oceanografia química para o aumento da qualidade da produção científica nacional e internacional. ${ }^{70}$

Hoje sabe-se que, seguindo as tendências globais, praticamente qualquer praia da extensa costa brasileira está em menor ou maior grau contaminada pela presença de plásticos. A poluição por plásticos em estuários do Brasil também é ubíqua, ${ }^{56,71,72}$ tendo sido relatada em diversas situações, inclusive por meio da ingestão de plásticos por peixes de interesse comercial e na conservação de recursos pesqueiros. ${ }^{52,73,74}$ Ambientes bentônicos parcial ou permanentemente submersos também se encontram indiscriminadamente contaminados. ${ }^{71,75}$ Os grupos de organismos que não residem permanentemente, mas frequentam a costa brasileira e suas ilhas, também encontram-se sujeitos à poluição por plásticos..$^{76,77} \mathrm{~A}$ origem da contaminação destes grupos é incerta, já que o problema da poluição por plásticos tem uma mobilidade que pode ser medida na escala de bacias oceânicas.

Nas ilhas oceânicas brasileiras a poluição marinha por plásticos segue o mesmo padrão relatado para outras ilhas do mundo, ${ }^{68}$ existindo basicamente duas fontes para esse tipo de poluição: fonte autóctone, relacionada ao uso intenso da ilha e outra marinha resultante de transporte, ou seja, alóctone. As fontes autóctones são mais preocupantes no Arquipélago de Fernando de Noronha, onde o fluxo intenso de pessoas e a demanda crescente por infraestrutura já não permite mais um controle eficiente das fontes de plásticos para os ambientes terrestres, de onde eles facilmente chegam às praias e ao mar. Já nas ilhas da Trindade e Martin Vaz, Atol das Rocas, Abrolhos e Arquipélago de São Pedro e São Paulo, a presença de pessoas é estritamente controlada e permite que a fonte local de lixo marinho também o seja. Restam então as fontes marinhas, alóctones, que resultam do transporte de lixo marinho - sobretudo plásticos - desde longas distâncias até suas praias. ${ }^{68}$

Em todos esses ambientes estão presentes itens grandes (inteiros ou fragmentados), facilmente identificáveis, mas a atenção tem atualmente se voltado para as frações menores, possivelmente mais danosas à fauna e flora marinhas, que são os microplásticos. ${ }^{78,79}$ Os microplásticos $(<5 \mathrm{~mm})$ em ambientes marinhos têm recebido bastante atenção da comunidade cientifica na última década, ${ }^{50,78}$ tendo inclusive merecido mais de uma dúzia de revisões da literatura (considerando-se apenas os artigos revisados por pares) nesse período de tempo. ${ }^{80}$ Essa fração de tamanho dos plásticos tem fundamentalmente duas naturezas, a primária que são os plásticos virgens (pellets) e a secundária que são os fragmentos resultantes da degradação física, química e biológica de itens maiores. Ambos os tipos oferecem os mesmos riscos ao ambiente marinho e sua biota: possibilidade de ingestão que leva a danos físicos ${ }^{78}$ e contaminação por poluentes orgânicos a eles (pré e/ou pós) associados. ${ }^{79} \mathrm{~A}$ maior parte da literatura internacional, incluindo trabalhos desenvolvidos no Brasil, trata dos microplásticos relatando sua presença nos diferentes compartimentos ambientais ${ }^{53,58,68}$ dentre eles a biota marinha..$^{52,73,74,76}$ Apenas recentemente houve trabalhos que começaram a investigar a associação entre plásticos e poluentes orgânicos ${ }^{77}$ buscando testar através de experimentos controlados, esse vínculo anteriormente suposto na literatura internacional. ${ }^{79}$

Outro fenômeno ligado à presença de poluição por plásticos no mar é o transporte de espécies animais e vegetais que os colonizam, ${ }^{81}$ e que também foi investigado no Brasil. ${ }^{61}$ Essa preocupação é cada dia mais presente também no continente Antártico. ${ }^{82}$ A durabilidade e a flutuabilidade de muitos itens e/ou materiais plásticos facilita o transporte através de longas distâncias. ${ }^{81}$

Apesar de estarem inseridos e fortemente ativos no contexto mundial de pesquisa em poluição marinha por plásticos, os grupos de pesquisa brasileiros em Oceanografia Química que lidam com o assunto ainda são poucos e esparsos. Algumas abordagens ainda precisam ser incentivadas nas suas linhas de pesquisa, a saber: experimentos controlados de ingestão de microplásticos contaminados por poluentes orgânicos e confirmação de danos por histologia; necropsias para verificação de danos físicos; resgate de informações sobre plásticos pelágicos em amostras de plâncton integrais guardadas em arquivos; caracterização química dos microplásticos pelágicos e bentônicos para confirmação de sua composição; avanços na fronteira do tamanho, passando-se a estudar também os nanoplásticos presentes em produtos de limpeza e higiene pessoal que chegam ao mar pelos esgotos domésticos; padronização de procedimentos de campo, laboratório e unidades de expressão dos resultados para permitir comparações espaço-temporais.

\section{Cafeína, cocaína, e outras drogas da indústria farmacêutica (humana e animal)}

Com os avanços alcançados pela química analítica instrumental e a melhoria da pureza dos reagentes nas últimas duas décadas, hoje, determina-se concentrações de compostos orgânicos e metabólitos em até partes por quadrilhão, mesmo em amostras de matrizes complexas. ${ }^{83,84}$ Com isso foi possível a determinação da presença não só de poluentes industriais de forte apelo junto à opinião pública (e.g. metais e hidrocarbonetos), mas também de substâncias, amplamente consumidas, de uso humano (e veterinário) como hormônios, medicamentos, cosméticos, drogas ilícitas e outras, como a cafeína e os legal highs. Os legal highs são extratos, comprimidos, pílulas, pós, fumos, chicletes e misturas de ervas comercializadas como alternativas legais às substâncias psicoativas regulamentadas, pois são produtos que imitam os efeitos das drogas ilícitas. Esse foi durante muito tempo um assunto negligenciado, mas sabe-se que o consumo de drogas, em geral, aumenta a pegada ecológica das populações de usuários de diversas formas, inclusive em termos de poluição aquática. Este é um problema antigo na sociedade e tem uma evolução quali-quantitativa relativamente bem conhecida no tempo e no espaço. Todas estas substâncias estão presentes em esgotos sanitários, efluentes tratados e até mesmo no escoamento superficial urbano que chegam aos corpos d'água receptores nas cidades e finalmente ao mar (Figura 4). Apesar de diluídas, estas substâncias são persistentes e chegam às águas costeiras em quantidades crescentes. Muito embora a quantidade de estudos realizados com estes compostos no ambiente marinho ao redor do mundo ainda seja reduzida, já existem registros de ocorrência de hormônios, ftalatos e alquilfenóis na zona costeira brasileira. ${ }^{85,86}$ Apesar de serem utilizadas por oferecerem conforto, segurança e

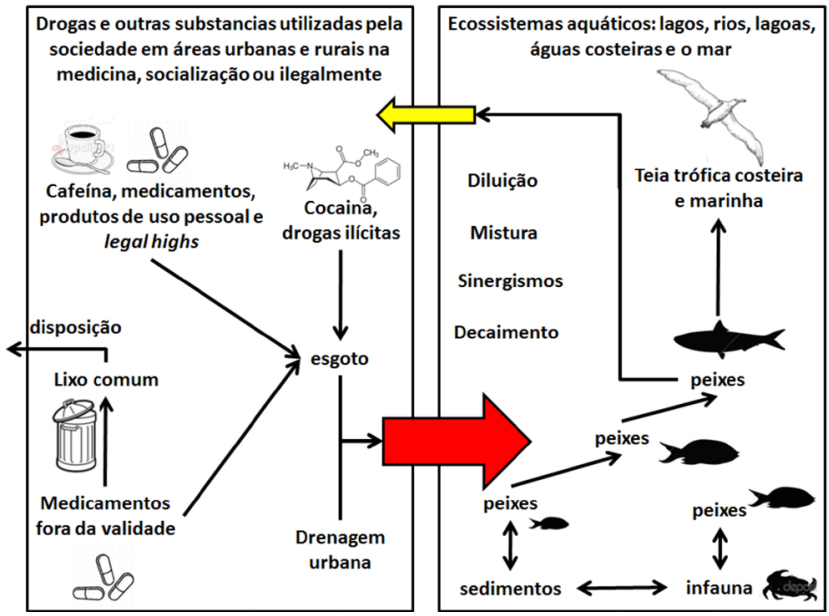

Figura 4. Fontes e destinos de substâncias amplamente consumidas, de uso humano (e veterinário) como hormônios, medicamentos, cosméticos, drogas ilícitas e outras, como a cafeína e os legal highs 
saúde (exceção às drogas ilícitas) à sociedade, no meio marinho estas substâncias, geralmente sintéticas, são compostos estranhos que continuam exercendo sua função química na fauna que a elas se expuser (Figura 4). Não há conhecimento bem consolidado de efeitos tóxicos na fauna costeira e marinha. Uma grande preocupação são as possíveis interferências que, por exemplo, os hormônios, alquilfenóis e ftalatos podem promover nos sistemas endócrinos dos animais marinhos.$^{87} \mathrm{O}$ crescimento do assunto na literatura cientifica internacional levou a tomadas de posição por parte de agencias governamentais, ${ }^{88}$ já que o assunto não pode mais ser ignorado.

\section{Isótopos estáveis e radioativos}

O estudo de processos oceanográficos com o uso de isótopos radioativos e estáveis é uma prática antiga e vem sendo utilizada nos últimos 60 anos. Isótopos estáveis permitem um melhor entendimento da história das massas d'água e fontes de elementos nutrientes chave para os oceanos, com implicações para o impacto da produção primária no ciclo global do carbono. ${ }^{89} \mathrm{O}$ neodímio, por exemplo, está sendo cada vez mais usado como traçador da circulação dos oceanos e, principalmente, na caracterização de diferentes fontes terrígenas de elementos. ${ }^{90}$

Muitos isótopos estáveis são assimilados e/ou metabolizados diferencialmente pelos processos biológicos (fracionamento isotópico) e cujas proporções em relação ao estoque total de isótopos do elemento são típicas de cada nível trófico. O uso dos isótopos estáveis de carbono e nitrogênio $\left({ }^{13} \delta \mathrm{C} ;{ }^{15} \delta \mathrm{N}\right)$ para a confirmação de processos ecológicos é cada vez mais frequente na Oceanografia Química e no Brasil. Um exemplo importante é o uso dessa técnica para acompanhar a biomagnificação de mercúrio, de origem antrópica, em teias tróficas costeiras e marinhas. ${ }^{91,92}$ Outras aplicações dos isótopos estáveis em estudos da área das ciências do mar são na aquicultura. ${ }^{93}$

Além destes, existem também os isótopos radioativos, naturalmente presentes nas amostras ambientais. Uma das informações mais frequentemente conseguidas a partir de isótopos radioativos é a datação de testemunhos de sedimentos e gelo com o uso de ${ }^{210} \mathrm{~Pb}$ e ${ }^{137} \mathrm{Cs} .{ }^{94}$ Isótopos radioativos (ex. ${ }^{203} \mathrm{Hg}$ ) também podem ser utilizados na avaliação de processos biogeoquímicos marinhos por meio de sua adição a experimentos controlados como, por exemplo, no estudo dos fluxos do ciclo do mercúrio através da superfície atmosfera-oceano, ${ }^{95,96}$ ou na avaliação da partição de contaminantes entre as fases dissolvidas e particuladas..$^{97,98}$

O emprego de isótopos no Brasil ainda é restrito devido à pequena disponibilidade de equipamentos. Entretanto, com o atual aumento do número dos espectrômetros de massa, sobretudo no Sudeste do país, abriram-se novas possibilidades de análise de amostras ambientais em maior numero e diversidade.

\section{Acidificação dos oceanos}

$\mathrm{O}$ aumento contínuo das emissões antropogênicas de $\mathrm{CO}_{2}$ para a atmosfera desde o início da Revolução Industrial há 250 anos (Figura 2) elevou a concentração de dióxido de carbono na atmosfera a níveis $40 \%$ superiores aos encontrados no período pré-industrial. ${ }^{99}$ Segundo o último balanço de emissões de carbono, ${ }^{100}$ foi previsto que em 2012 as emissões antropogênicas de $\mathrm{CO}_{2}$ atinjam $9.7 \pm 0.5 \mathrm{PgC}$.

Aproximadamente $1 / 4$ das emissões anuais de $\mathrm{CO}_{2}$ antropogênico é absorvido pelos oceanos. Se por um lado o impacto das emissões na intensificação do efeito estufa na atmosfera é diminuído, o "custo ambiental" é muito elevado: quando o $\mathrm{CO}_{2}$ atmosférico é absorvido pelos oceanos, ele é dissolvido na água do mar. O resultado deste processo é a formação de ácido carbônico nas camadas superficiais dos oceanos, por meio de uma reação química que leva à acidificação dos oceanos (Figura 5). A "acidez" dos oceanos já aumentou em aproximadamente $30 \%$ desde o começo da revolução industrial. ${ }^{101}$

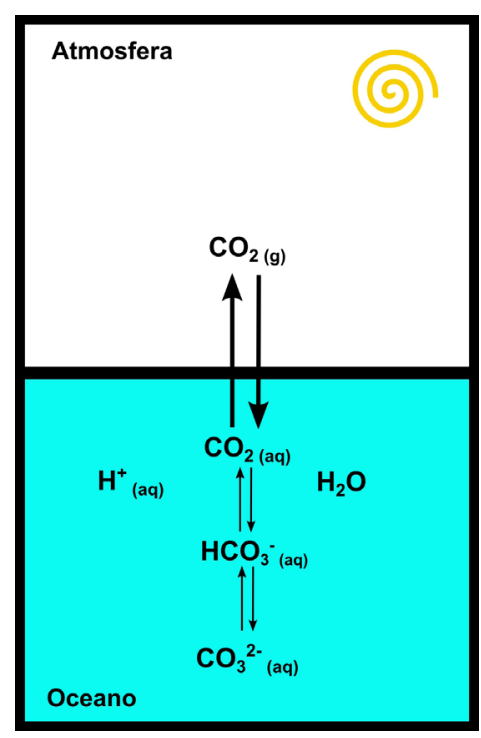

Figura 5. Representação esquemática do equilíbrio químico do sistema carbonato - dióxido de carbono na água do mar

Entende-se por acidificação a redução do $\mathrm{pH}$ dos oceanos por longos períodos de tempo (décadas ou mais). ${ }^{102}$ Esta redução do $\mathrm{pH}$ é causada principalmente pela dissolução do $\mathrm{CO}_{2}$ atmosférico nos oceanos. Este processo torna a água do mar mais "corrosiva" para os organismos que produzem conchas e outras estruturas calcárias, podendo afetar também a sua reprodução, fisiologia e distribuição geográfica. ${ }^{103}$ Caso o ritmo atual de emissões antropogênicas de $\mathrm{CO}_{2}$ e consequente diminuição do $\mathrm{pH}$ das águas superficiais seja mantido, dentro de poucas décadas a água do mar não sustentará mais o desenvolvimento de ecossistemas coralinos (tanto as espécies tropicais quanto as espécies de águas profundas e frias - ambas presentes na costa e na margem continental brasileira, ${ }^{104} \mathrm{e}$ de outros organismos que produzam estruturas calcárias (i.e. conchas e exoesqueletos), como os mexilhões e algas calcárias. ${ }^{103,105} \mathrm{O}$ desenvolvimento destes organismos estará tão prejudicado pela acidificação dos oceanos que haverá mais erosão que crescimento (no caso dos recifes coralinos e dos bancos de rodolitos da plataforma continental leste brasileira). Em algumas regiões e sob determinadas condições, a vida nos oceanos para certos organismos pode tornar-se impossível. ${ }^{103,106}$ Isto levará à perda de biodiversidade e a impactos econômicos ligados aos recursos pesqueiros e atividades relacionadas ao turismo. ${ }^{107} \mathrm{~A}$ destruição/declínio de recifes coralinos afeta diretamente a biodiversidade marinha, o turismo e a produção pesqueira, já que estes ecossistemas funcionam como zona berçário para muitas espécies de interesse comercial. O declínio e a erosão de recifes coralinos podem ainda diminuir a proteção do litoral contra eventos extremos, como por exemplo, tempestades. ${ }^{99}$ Finalmente, o aumento da acidificação, junto com o aumento da temperatura dos oceanos, diminui a capacidade de absorção do $\mathrm{CO}_{2}$ em excesso, o que cria um círculo vicioso de aumento da temperatura e aumento dos efeitos de aquecimento da atmosfera. ${ }^{107,108}$

Outro aspecto ainda pouco estudado da mudança no decréscimo do $\mathrm{pH}$ marinho (e consequente decréscimo nas concentrações de $\mathrm{OH}^{-}$e $\mathrm{CO}_{3}^{-}$nos oceanos) é o efeito destas mudanças na especiação química de metais que formam complexos (mono-, di-, e trivalentes) com os dois íons citados (Tabela 1). ${ }^{109,110}$ As mudanças na especiação de certos metais, provocadas pela acidificação, causarão também 
mudanças na solubilidade de vários metais. Por exemplo, o ferro trivalente $(\mathrm{Fe}(\mathrm{III}))$ encontra-se na sua faixa de menor solubilidade no $\mathrm{pH}$ médio atual dos oceanos. ${ }^{111}$ Uma diminuição drástica no $\mathrm{pH}$, de 8,1 para 7,4 aumentaria a solubilidade do $\mathrm{Fe}$ (III) em até $40 \%$. Este aumento da solubilidade do Fe(III) pode ter efeitos diretos nos ciclos biogeoquímicos marinhos, já que o ferro é um micronutriente essencial para o plâncton, conforme previamente discutido. ${ }^{110,112,113}$ Uma maior biodisponibilidade de ferro para o fitoplâncton marinho pode levar a um aumento da produção primária nos oceanos devido ao efeito de fertilização e consequente transferência de $\mathrm{CO}_{2}$ atmosférico para os oceanos. ${ }^{114-116}$

Cabe aqui ressaltar que medidas de mitigação dos impactos climáticos (redução da temperatura global, redução nas emissões dos outros gases de efeito estufa) não têm nenhum efeito sobre o problema da acidificação dos oceanos. A acidificação não é causada pelas mudanças climáticas globais, como o aumento da temperatura média do planeta, mas é considerado o outro problema relacionado às emissões antropogênicas de $\mathrm{CO}_{2},{ }^{106}$ e não é reversível na escala de tempo de vidas humanas. ${ }^{108}$ Ainda que fosse possível cortar imediatamente as emissões de $\mathrm{CO}_{2}$, a quantidade de $\mathrm{CO}_{2}$ emitida pelo homem até hoje permanecerá na atmosfera ainda por alguns milhares de anos, mantendo as temperaturas do planeta elevadas em relação ao período pré-industrial, e dissolvendo-se na superfície dos oceanos, provocando a acidificação. ${ }^{108,117,118}$

Apesar das iniciativas globais de observação (GOOS, VOSCDIAC, JGOFS, CLIVAR), os oceanos continuam "subamostrados" em relação aos parâmetros necessários para entender os efeitos da acidificação: muitas observações restringem-se às camadas superficiais ou a escalas de tempo que não são adequadas a estudos de certos processos oceanográficos, como a variabilidade sazonal e intra diária da pressão parcial de $\mathrm{CO}_{2}, \mathrm{pH}$ ou alcalinidade nos oceanos e nas zonas costeiras. ${ }^{118-120}$ Além do mais, comumente os equipamentos de

Tabela 1. Especiação de alguns metais na água do mar, estimadas em função do tempo (ano) e do pH médio da água do mar (escala livre de pH), a $25{ }^{\circ} \mathrm{C}$ e salinidade 35, levando em conta a tendência atual de acidificação dos oceanos. Tabela adaptada de Millero e colaboradores ${ }^{110}$

\begin{tabular}{|c|c|c|c|c|c|c|c|c|}
\hline & \multicolumn{8}{|c|}{ Ano } \\
\hline & 2000 & 2050 & 2070 & 2085 & 2100 & 2150 & 2200 & 2250 \\
\hline$\underline{p H}$ & 8,1 & 8 & 7,9 & 7,8 & 7,7 & 7,6 & 7,5 & 7,4 \\
\hline \multicolumn{9}{|c|}{ Espécies metálicas } \\
\hline $\mathrm{Al}(\mathrm{OH})_{3}$ & 32,18 & 37,34 & 42,76 & 48,32 & 53,82 & 59,10 & 63,98 & 68,30 \\
\hline $\mathrm{Al}(\mathrm{OH})_{4}^{-}$ & 67,53 & 62,24 & 56,63 & 50,81 & 44,96 & 39,22 & 33,72 & 28,59 \\
\hline $\mathrm{Cu}^{2+}$ & 7,67 & 9,64 & 12,04 & 14,92 & 18,32 & 22,26 & 26,75 & 31,76 \\
\hline $\mathrm{CuOH}^{+}$ & 4,70 & 4,70 & 4,66 & 4,59 & 4,47 & 4,30 & 4,12 & 3,88 \\
\hline $\mathrm{CuCO}_{3}$ & 66,98 & 68,51 & 69,25 & 69,14 & 68,14 & 66,25 & 63,50 & 59,56 \\
\hline $\mathrm{Cu}(\mathrm{CO} 3)_{2}{ }^{2-}$ & 18,34 & 15,26 & 12,49 & 10,05 & 7,95 & 6,18 & 4,70 & 3,55 \\
\hline $\mathrm{CuSO}_{4}$ & - & - & - & - & - & - & - & - \\
\hline $\mathrm{Gd}^{3+}$ & 3,37 & 4,48 & 5,91 & 7,71 & 9,93 & 12,59 & 15,71 & 19,27 \\
\hline $\mathrm{GdCO}_{3}^{+}$ & 47,53 & 51,46 & 54,95 & 57,77 & 59,71 & 60,59 & 60,31 & 58,84 \\
\hline $\mathrm{Gd}\left(\mathrm{CO}_{3}\right)_{2}^{-}$ & 46,78 & 41,20 & 35,61 & 30,17 & 25,03 & 20,33 & 16,14 & 12,52 \\
\hline $\mathrm{GdSO}_{4}^{+}$ & 0,86 & 1,15 & 1,51 & 1,98 & 2,54 & 3,23 & 4,02 & 4,94 \\
\hline $\mathrm{GdCl}_{2}^{+}$ & 0,49 & 0,65 & 0,85 & 1,11 & 1,43 & 1,82 & 2,27 & 2,78 \\
\hline $\mathrm{Pb}^{2+}$ & 2,89 & 3,29 & 3,70 & 4,13 & 4,56 & 4,99 & 5,39 & 5,77 \\
\hline $\mathrm{PbOH}^{+}$ & 4,24 & 3,83 & 3,40 & 3,03 & 2,66 & 2,31 & 1,98 & 1,68 \\
\hline $\mathrm{PbCO}_{3}$ & 59,03 & 54,53 & 49,72 & 44,71 & 39,64 & 34,65 & 29,88 & 25,43 \\
\hline $\mathrm{PbCl}^{+}$ & 13,09 & 14,86 & 16,74 & 18,68 & 20,63 & 22,54 & 24,37 & 26,07 \\
\hline $\mathrm{PbCl}_{2}$ & 14,09 & 16,00 & 18,02 & 20,10 & 22,21 & 24,60 & 26,3 & 28,06 \\
\hline $\mathrm{PbCl}^{3-}$ & 6,40 & 7,27 & 8,19 & 9,14 & 10,09 & 11,03 & 11,93 & 12,76 \\
\hline $\mathrm{Cd}^{2+}$ & 20,15 & 20,17 & 20,18 & 20,19 & 20,20 & 20,21 & 20,21 & 20,22 \\
\hline $\mathrm{CdCl}^{ \pm}$ & 43,71 & 43,75 & 43,78 & 44,10 & 43,82 & 43,80 & 43,85 & 43,86 \\
\hline $\mathrm{CdCl}_{2}$ & 27,70 & 27,72 & 27,74 & 28,07 & 27,77 & 27,78 & 27,79 & 27,79 \\
\hline $\mathrm{CdCl}^{3-}$ & 7,95 & 7,95 & 7,96 & 7,97 & 7,96 & 7,97 & 7,97 & 7,97 \\
\hline $\mathrm{HgCl}_{2}$ & 11,80 & 11,80 & 11,80 & 11,80 & 11,80 & 11,80 & 11,80 & 11,80 \\
\hline $\mathrm{HgCl}_{3}^{-}$ & 88,20 & 88,20 & 88,20 & 88,20 & 88,20 & 88,20 & 88,20 & 88,20 \\
\hline $\mathrm{Fe}^{2+}$ & 65,99 & 70,42 & 74,57 & 78,36 & 81,76 & 84,75 & 87,33 & 89,53 \\
\hline $\mathrm{FeCO}_{3}$ & 32,00 & 27,78 & 23,81 & 20,16 & 16,89 & 14,00 & 11,51 & 9,39 \\
\hline $\mathrm{FeOH}$ & 1,40 & 1,20 & 1,01 & 0,84 & 0,69 & 0,57 & 0,47 & 0,38 \\
\hline $\mathrm{Ni}^{2+}$ & 68,29 & 72,48 & 76,37 & 79,91 & 83,10 & 85,79 & 88,15 & 90,12 \\
\hline $\mathrm{NiCO}_{3}$ & 30,29 & 26,15 & 22,30 & 18,80 & 15,69 & 12,97 & 10,63 & 8,64 \\
\hline $\mathrm{Co}^{2+}$ & 92,58 & 93,81 & 94,84 & 95,69 & 96,39 & 96,97 & 97,44 & 97,82 \\
\hline $\mathrm{CoCO}_{3}$ & 5,30 & 4,37 & 3,57 & 2,91 & 2,35 & 1,89 & 1,51 & 1,21 \\
\hline $\mathrm{CoOH}$ & 1,45 & 1,16 & 0,93 & 0,75 & 0,60 & 0,48 & 0,38 & 0,30 \\
\hline $\mathrm{Zn}^{2+}$ & 80,58 & 84,41 & 87,45 & 89,85 & 91,74 & 93,22 & 94,38 & 95,29 \\
\hline $\mathrm{ZnOH}^{+}$ & 5,65 & 4,70 & 3,87 & 3,15 & 2,56 & 2,06 & 1,66 & 1,33 \\
\hline $\mathrm{ZnCO}_{3}$ & 7,16 & 6,10 & 5,10 & 4,20 & 3,47 & 2,82 & 2,28 & 1,83 \\
\hline $\mathrm{Mn}^{2+}$ & 97,34 & 97,70 & 98,08 & 98,36 & 98,60 & 98,77 & 98,93 & 99,05 \\
\hline
\end{tabular}


observações oceanográficas em estações temporais são desprovidos de sensores e/ou equipamentos que sirvam a aumentar o entendimento da química do carbono $\left(\mathrm{CO}_{2}\right)$ dissolvido na água do mar e dos efeitos do processo de acidificação dos oceanos na biogeoquímica e na especiação de elementos traço, ${ }^{109}$ além dos efeitos sobre os organismos marinhos.

A pesquisa científica sobre a acidificação e suas implicações para os processos biogeoquímicos globais e seus efeitos sobre os organismos marinhos é relativamente recente, apesar da sua importância global. ${ }^{107}$ Nos últimos vinte anos, a determinação das variáveis relacionadas ao gás carbônico dissolvido na água do mar $(\mathrm{pH}$, alcalinidade total, carbono inorgânico dissolvido, pressão parcial do $\mathrm{CO}_{2}$ ) vem se intensificando, assim como o desenvolvimento de métodos analíticos, sensores mais precisos e duráveis (ex: sensores de pH DURAFETC ${ }^{121}$ e material certificado para a sua determinação). ${ }^{122,123}$

No Brasil, a investigação sobre os efeitos da acidificação está ainda em estágio inicial. Os dados disponíveis sobre o sistema carbonato marinho na plataforma continental brasileira são esparsos (Figura 6). O grande desafio presente é intensificar as observações oceanográficas de longa duração tanto em ambientes costeiros quanto em área oceânicas, assim como a disponibilização, preferencialmente sob a forma de plataforma eletrônica, de dados de programas de pesquisa anteriores (REVIZEE, HABITAT), onde os parâmetros químicos relativos à acidificação foram medidos. Segundo um relatório recente sobre a investigação sobre acidificação no Brasil, ${ }^{124}$ as prioridades de pesquisa para a compreensão dos efeitos da acidificação nos mares brasileiros incluem o monitoramento a longo prazo (ecossistemas costeiros e oceânicos), estudos laboratoriais e in situ para avaliar os efeitos sobre a biota, modelagem biogeoquímica de processos ligados à química do $\mathrm{CO}_{2}$ no mar, e estudos paleoceanográficos. Em longo prazo, espera-se que os pesquisadores envolvidos com a pesquisa em acidificação no Brasil (profissionais químicos, oceanógrafos, biólogos, geólogos, físicos) sejam capazes de identificar as zonas vulneráveis e propor medidas de mitigação e de proteção dos impactos decorrentes da acidificação.

\section{DESAFIOS}

O ambiente marinho certamente representa um dos sistemas mais complexos para serem estudados, devido não apenas aos desafios impostos pela natureza das águas, mas especialmente devido às interações dos processos físicos, químicos e biológicos que controlam os ciclos biogeoquímicos dos elementos em tempos de grandes mudanças globais decorrentes dos impactos antrópicos. Complementarmente, as dificuldades operacionais e financeiras associadas ao custeio de programas de pesquisa em águas oceânicas têm, historicamente, restringindo a maioria das ações da oceanografia química brasileira em águas continentais e costeiras.

Hoje, no panorama nacional, o principal desafio é ter uma agenda de Estado para a educação, ciência e tecnologia focada nas ciências do mar e que, ao longo prazo, permita ampliar e consolidar as competências de modo a permitir uma maior inserção internacional e a diminuição nas diferenças regionais ainda significativas ao longo do Brasil. Os Institutos Nacionais de Ciências e Tecnologias (INCTs) em ciências do mar, o programa Ciência sem Fronteiras, no qual a área ciências do mar é contemplada, e a recente criação do Instituto Nacional de Pesquisas Oceanográficas e Hidroviárias (INPOH) representam um excelente começo. Estas recentes oportunidades encerram grandes desafios e abrirão espaços para o desenvolvimento da oceanografia química brasileira e outras áreas.

No panorama internacional, passados 40 anos dos primeiros esforços, a comunidade acadêmica encontra-se hoje em posição privilegiada para executar o primeiro estudo de escala global para observação de elementos traço e seus isótopos no ambiente marinho, bem como avaliar os efeitos das grandes mudanças globais associadas às consequências das megacidades distribuídas ao redor do globo. Esta ação só será possível devido ao amplo desenvolvimento e disseminação em técnicas analíticas e procedimentos limpos para coleta de amostras, somado a um amplo esforço internacional concertado em objetivos claros para expandir as fronteiras da biogeoquímica dos oceanos e áreas afins, incluindo as questões de mudança climática, poluição e acidificação dos oceanos associadas a alterações no ciclo do carbono. É esperado que os dados oceanográficos sobre os mais diversos aspectos da química dos oceanos produzidos nesta próxima década possibilitem o melhor entendimento dos ciclos biogeoquímicos, mas especialmente permitam a avaliação das variações dos elementos traço e contaminantes nos oceanos devido as influencias antrópicas, bem como seus efeitos nos ecossistemas e clima. Modelos computacionais deverão ser construídos para simular as condições e processos dos oceanos modernos e permitir previsões do futuro. Estes modelos vão requerer um bom conhecimento dos sistemas oceânicos, os quais além de serem extremamente complexos, apresentam múltiplos feedbacks.

Muitos desafios analíticos ainda deverão ser vencidos, especialmente com relação à especiação química dos elementos e a determinação de espécies orgânicas e inorgânicas (e.g. metais nobres) não resolvidas. Esforços concertados de programas de pesquisa como o GEOTRACES e ações isoladas de grupos de pesquisa já estão em andamento. A participação da comunidade acadêmica brasileira nestas mais recentes investidas na fronteira da Oceanografia Química é extremamente limitada, especialmente devido a: $i$. ausência de infraestrutura física para preparo de material de campo e processamento de amostras em nível ultra traço; ii. acesso limitado em cruzeiros oceanográficos, seja devido ao pequeno número de embarcações brasileiras e/ou ausência de laboratórios/containers "limpos" nestas embarcações; iii. reduzida cooperação internacional; $i v$. restrita capacidade analítica das instituições brasileiras para a análise de elementos traço e ultratraço (e.g. REE) em água do mar; $v$. alto custo de reagentes ultrapuros associado ao processamento de um grande número de amostras; e vi. falta de capacitação de pessoal de nível técnico e superior nesta área da Oceanografia.

Embora o Brasil seja signatário da MARPOL, uma responsabilidade assumida em nível internacional há décadas, apenas recentemente, o país regulamentou instrumentos legais internos e integradores que tratam de questões relacionadas à geração, tratamento e disposição de resíduos sólidos, a se somarem a tantos outros que já existiam sobre os resíduos líquidos e assuntos dispersos (pneumáticos inservíveis, lixo hospitalar, etc.).

O que se observa atualmente é uma crescente preocupação com relação à integridade dos ecossistemas, especialmente com relação ao aporte de contaminantes. Infelizmente esta classe grande e diversa de compostos e materiais tende a crescer nos oceanos à medida que novos produtos químicos e materiais são diariamente desenvolvidos e lançados nos corpos d'água. Este é o caso da contaminação das águas por REE, considerados antigamente como elementos "exóticos". Como considerar a importância deste e outros impactos? Muitos produtos, como é o caso de alguns fármacos, retardantes de chama, alquilfenóis, hidrocarbonetos, pesticidas, entre outros, que apresentam conhecida interferência endócrina ${ }^{125-127}$ e drogas ilícitas ${ }^{128,129}$ não são eficazmente retidos nos sistemas de tratamento de águas e esgotos e mesmo em concentrações diminutas, devidos a processos de atenuação, tendem a chegar à zona costeira e, potencialmente, aos oceanos. ${ }^{130} \mathrm{O}$ estudo destas substâncias no ambiente marinho, globalmente, ainda é muito reduzido para sabermos ao certo o impacto que poderão causar. Portanto, a toxicidade, o destino, o transporte e o comportamento destes microcontaminantes devem ser estudados em detalhe em todos os compartimentos ambientais. 

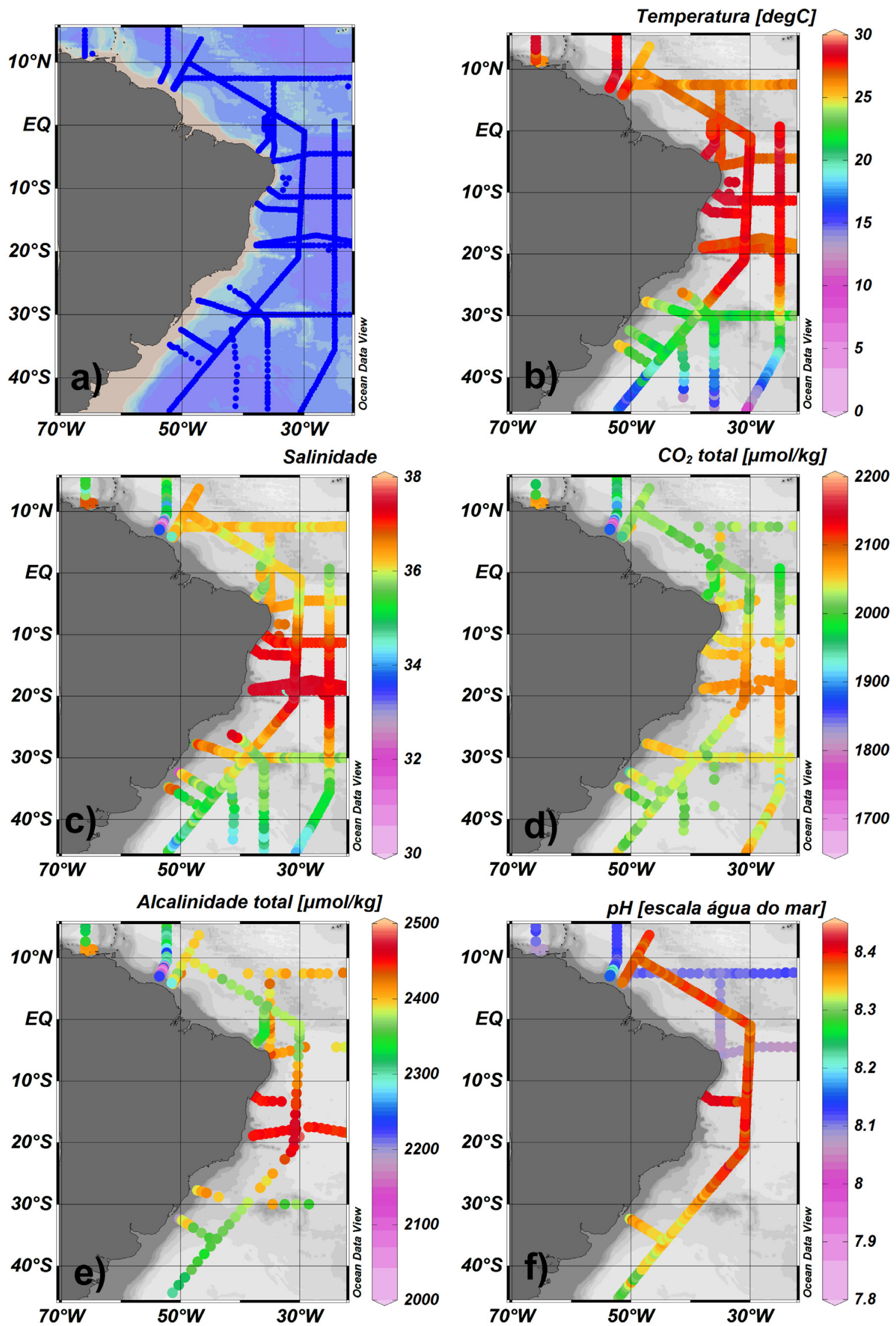

Figura 6. Dados disponíveis para o sistema carbonato em águas superficiais no oceano Atlântico sul (tropical e subtropical, incluindo a plataforma continental

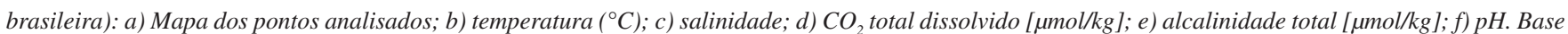
de dados GLODAP (Global Ocean Data Analysis Project). ${ }^{133}$ Gráficos preparados com o programa Ocean Data View ${ }^{134}$ 
No passado, muitas previsões foram feitas para os rumos da Química Ambiental, da química das águas naturais e da Oceanografia Química, ${ }^{131,132}$ várias das quais se materializaram. O futuro aponta para que as pesquisas sejam cada vez mais interdisciplinares, nas quais a questão da sustentabilidade e a química limpa desempenharão um papel fundamental. Os avanços em termos de conhecimento e recursos analíticos hoje disponíveis oferecem condições favoráveis para a oceanografia química crescer. A comunidade acadêmica brasileira está amadurecendo e está disposta a desempenhar um papel de destaque no fortalecimento das ciências do mar, e das conexões destas com a educação e inovação tecnológica em prol da preservação dos oceanos e desenvolvimento da sociedade.

\section{AGRADECIMENTOS}

À Diretoria e ao Conselho da Sociedade Brasileira de Química, pela iniciativa em produzir este Número Especial e aos Editores de Química Nova e deste volume. V. Hatje e M. F. da Costa agradecem as bolsas de pesquisa concedidas pelo CNPq.

\section{REFERÊNCIAS}

1. Pinto, A. C.; Zucco, C.; de Andrade, J. B.; Vieira, P. C.; Quim. Nova 2012, 35, 2092.

2. Anbar, A. D.; Science 2008, 322, 1481.

3. Holland. H. D. Em The Oceans and Marine Geochemistry, Elderfield, H., ed.; Elsevier-Pergamon: Oxford, 2003, p. 583.

4. Canfield, D. E.; Annu. Rev. Earth Planet. Sci. 2005, 33, 1.

5. Saito, M. A.; Inorg. Chim. Acta 2003, 356, 308.

6. Matsumoto, K.; J. Geophys. Res. 2007, 112, 1.

7. Nozaki, Y. Em Encyclopedia of Ocean Sciences; Steele, J. H.; Thorpe, S. A.; Turekian, K. K., eds.; Academic Press: San Diego, 2001, p. 840.

8. Bruland, K. W.; Lohan, M. C. Em The Oceans and Marine Geochemistry: Elderfield, H., ed.; Elsevier-Pergamon: Oxford, 2003, p. 23.

9. Sarmiento, J. L.; Gruber, N.; Ocean Biogeochemical Dynamics, Princeton University Press: Princeton, 2006.

10. Chester, R.; Marine Geochemistry, $3^{\text {rd }}$ ed., Blackwell Science: UK, 2012.

11. Millero, F.; Chemical Oceanography, $3^{\text {rd }}$ ed., CRC: Washington, 2009.

12. Nozaki, Y.; Trans. Am. Geophys. Union 1997, 78, 221.

13. http://www.mbari.org/chemsensor/pteo.htm, acessada em Julho 2013.

14. Moore, J. K.; Doney, S. C.; Lindsay, K.; Global Biogeochem. Cycles 2004, 18, 4028; Martin, J. H.; Fitzwater, S. E.; Gordon, R. M.; Global Biogeochem. Cycles 1990, 4, 5.

15. Morel, F. M. M.; Price, N. M.; Science 2003, 300, 944

16. Sigman, D. M.; Boyle, E. A.; Nature 2000, 407, 859.

17. Morel, F. M. M.; Milligan, A. J.; Saito, M. A. Em Treatise on Geochemistry - The Oceans and Marine Geochemistry v.6; Elderfield, H., ed.; Elsevier-Pergamon: Oxford, 2004, pp. 113-143.

18. Sohrin, Y.; Bruland, K. W.; TrAC Trends Anal. Chem. 2011, 30, 1291.

19. de Baar, H. J. W.; de Jong, J. T. M. Em IUPAC Book Series on Analytical and Physical Chemistry of Environmental Systems v.7; Turner, D. R.; Hunter, K. A., eds.; Wiley: Chichester, 2001, pp. 123-253.

20. Bruland, K. W.; Lohan, M. C. Em Treatise on Geochemistry - The Oceans and Marine Geochemistry v.6; Elderfield, H., ed.; ElsevierPergamon: Oxford, 2004, pp. 23-47.

21. Broecker, W. S.; Peng, T.-H., Tracers in the Sea. Eldigio Press, LamontDoherty Geological Observatory, New York, 1982.

22. Henderson, G. M.; Earth Planet. Sci. Lett. 2002, 203, 1.

23. Henderson, G. M.; Anderson, R. F.; Rev. Mineral. Geochem. 2003, 52, 493.

24. Cleroux, C.; Cortjo, E.; Anand, P.; Labeyrie, L.; Bassinot, F.; Caillon, N.; Duplessy, J. C.; Paleoceanography 2008, 23, PA3214.

25. Yu, J; Elderfield, H.; Earth Planet. Sci. Lett. 2007, 258, 73.
26. GEOTRACES Planning Group, GEOTRACES Science Plan, Scientific Committee on Oceanic Research, Baltimore, MD, USA, 2006.

27. Steinacher, M.; Joos, F.; Frölicher, T. L.; Bopp, L.; Cadule, P.; Cocco, V.; Doney, S. C.; Gehlen, M. ; Lindsay, K.; Moore, J. K.; Schneider, B.; Segschneider; Biogeosciences 2010, 7, 979.

28. Volk, T.; Hoffert, M. I. Em The Carbon Cycle and Atmospheric $\mathrm{CO}_{2}$ : Natural Variations Archean to Present, Geophys. Monogr. Ser. 32; Sundquist, E. T.; Broecker, W. S., eds.; AGU: Washington, 1985, pp. $99-110$

29. Suntharalingam, P.; Sarmiento, J. L.; Cycles 2000, 14, 429.

30. Bopp, L.; Aumont, O.; Belviso, S.; Monfray, P.; Tellus B 2003, 55, 11.

31. Manizza, M.; Le Quéré, C. L.; Watson, A. J.; Buitenhuis, E. T.; J. Geophys. Res. Oceans 2008, 113, 772.

32. Albanese, S.; Cicchella, D.; Elements 2012, 8, 423.

33. USA Census Bureau, http://www.census.gov/popclock/, acessada em Julho 2013.

34. Crutzen, P. J.; Nature 2002, 415, 23.

35. http://keelingcurve.ucsd.edu/, acessada em Julho 2013.

36. Sigman, D. M; Boyle, E. A.; Nature 2000, 407, 859.

37. United Nations; World urbanization prospects, the 2011 Revision. United Nations, New York. 2012.

38. Meybeck, M.; Phil. Trans. R. Soc. B 2003, 358, 1935.

39. Newton, A.; Carruthers, T. J. B.; Icely, J.; Estuarine Coastal Shelf Sci. 2012, 96, 39.

40. Tan, B. L. L.; Hawker, D. W.; Müller, J. F.; Leusch, F. D. L.; Tremblay, L. A; Chapman, H. F.; Environ. Int. 2007, 33, 654

41. Toze, S.; Agric. Water Manage. 2006, 80, 147.

42. Xu, J.; Wang, P.; Guo, W.; Dong, J.; Wang, L.; Dai, S.; Chemosphere 2006, 65, 1445 .

43. Johnson, A. C.; Williams, R. J.; Simpson, P.; Kanda, R.; Environ. Pollut. 2007, 147, 194

44. Kulaksiz, S.; Bau, M.; Appl. Geochem. 2011, 26, 1877; Barber, L. B; Murphy, S. F.; Verplanck, P. L.; Sandstro, M. W.; Taylor, H. E. T; Furlong, E.T.; Environ. Sci. Technol. 2006, 40, 475; Lyons, W. B.; Harmon, R. S.; Elements 2012, 8, 417.

45. Bau, M.; Dulski, P.; Earth Planet. Sci. Lett. 1996, 143, 245.

46. Elbaz-Poulichet, F.; Seidel, J.-L.; Othoniel, C.; Water Research 2002, 36, 1102; Bau, M.; Knappe, A.; Dulski, P.; Geochemistry 2006, 66, 143; Möller, P.; Morteani, G.; Dulski, P.; Acta Hydroch. Hydrob. 2003, 31, 225; Lawrence, M. G.; Jupiter, S. D.; Kamber, B. S.; Aust. J. Mar. Freshwater Res. 2006, 57, 725; Kulaksız, S.; Bau, M.; Environ Int. 2011, 37, 973; Kulaksız, S.; Bau, M.; Earth Planet. Sci. Lett. 2013, 362, 43.

47. Halpern, B. S.; Longo, C.; Hardy, D.; McLeod, K. L.; Samhouri, J. F.; Katona, S. K.; Kleisner, K.; Lester, S.E.; O’Leary, J.; Ranelletti, M.; Rosenberg, A. A.; Scarborough, C.; Selig, E. R.; Best, B. D.; Brumbaugh, D. R.; Chapin, F. S.; Crowder, L. B.; Daly, K. L.; Doney, S. C.; Elfes, E.; Fogarty, M. J.; Gaines, S. D.; Jacobsen, K. I.; Karrer, L. B.; Leslie, H. M.; Neeley, E.; Pauly, D.; Polasky, S.; Ris, B.; St Martin, K.; Stone, G. S.; Sumaila, U. R.; Zeller, D.; Nature 2012, 488, 615.

48. UNEP. Marine Litter: An Analytical Overview. UNEP: Nairobi, 2005.

49. Moore, C. J.; Environ. Res. 2008, 108, 131.

50. Andrady, A. L.; Mar. Pollut. Bull. 2011, 62, 1596.

51. Ivar do Sul, J. A.; Costa, M. F.; Mar. Pollut. Bull. 2007, 54, 1087.

52. Ramos, J. A. A.; Barletta, M.; Costa, M. F.; Aquat. Biol. 2012, 17, 29.

53. Fisner, M.; Taniguchi, S.; Moreira, F.; Bícego, M. C.; Turra, A.; Mar. Pollut. Bull. 2013, 70, 219.

54. Thompson, R. C.; Moore, C. J.; Vom Saal, F. S.; Swan, S. H. Phil. Trans. R. Soc. B 2009, 364, 1526.

55. Coe, J. M.; Rogers, D. B.; Marine Debris: sources, impacts and solutions. Springer-Verlag: New York, 2000.

56. Ivar do Sul, J. A.; Costa, M. F.; J. Coast. Res. 2013, SI65, 48.

57. Santos, I. R.; Friedrich, A. C.; Ivar Do Sul, J. A.; Environ. Monit. Assess. 2009, 148,455 . 
58. Costa, M. F.; Ivar do Sul, J. A.; Silva-Cavalcanti, J. S.; Araujo, M. C. B.; Spengler, A.; Tourinho, P. S.; Environ. Monit. Assess. 2010, 168, 299.

59. Ivar do Sul, J. A.; Santos, I. R.; Friedrich, A. C.; Matthiensen, A.; Fillmann, G.; Estuaries Coasts 2011, 34, 814.

60. Silva, J. S.; Barbosa, S. C. T.; Costa, M. F.; J. Coast. Res. 2008, 24, 890

61. Widmer, W. M.; Hennemann, M. C.; J. Coast. Res. 2010, 26, 993.

62. Silva, J. S.; Araújo, M. C. B.; Costa, M. F.; Waste Manage. Res. 2009, $27,93$.

63. Tourinho, P. S.; Ivar do Sul, J. A.; Fillmann, G.; Mar. Pollut. Bull. 2010 $60,396$.

64. Ivar do Sul, J. A.; Rodrigues, O.; Santos, I. R.; Fillmann, G.; Matthiensen, A.; Ecotoxicol. Environ. Saf. 2009, 72, 2020.

65. Guebert-Bartholo, F. M.; Barletta, M.; Costa, M. F.; Monteiro-Filho, E. L. A.; Endang. Species Res. 2011, 13, 131.

66. Ivar do Sul, J. A.; Costa, M. F.; Alves, L. H. B.; 2013. Proceedings of the Untangled symposium: Exploring the impact of marine debris on animal welfare and seeking animal-focused solutions. Miami, Estados Unidos, 2013.

67. Portz, L.; Manzolli, R. P.; Ivar Do Sul, J. A.; Journal of Integrated Coastal Zone Management 2011, 11, 41.

68. Ivar do Sul, J. A.; Spengler, A.; Costa, M. F.; Mar. Pollut. Bull. 2009, 58, 1229.

69. Machado, A. A.; Fillmann, G.; Journal of Integrated Coastal Zone Management 2010, 10, 381.

70. Lacerda, L. D.; Marins, R. V.; Quim. Nova 2010, 33, 1005.

71. Costa, M. F.; Silva-Cavalcanti, J. S.; Barbosa, C. C.; Portugal, J. L.; Barletta, M.; J. Coast. Res. 2011, SI64, 339.

72. Ramos, J. A. A.; Barletta, M.; Dantas, D. V.; Lima, A. R. A.; Costa, M. F.; J. Fish Biol. 2011, 78, 344.

73. Possatto, F. E.; Barletta, M.; Costa, M. F.; Ivar do Sul, J. A.; Dantas, D. V.; Mar. Pollut. Bull. 2011, 62, 1098.

74. Dantas, D. V.; Barletta, M.; Costa, M. F.; Environ. Sci. Pollut. Res. Int. 2011, 19, 600 .

75. Spengler, A; Costa, M. F.; Mar. Pollut. Bull. 2008, 56, 226.

76. Colabuono, F. I.; Barquete, V; Domingues, B; Montone, R.; Mar. Pollut. Bull. 2009, 58, 93.

77. Colabuono, F. I.; Taniguchi, S.; Montone, R. C.; Mar. Pollut. Bull. 2010, 60,630 .

78. Wright, S. L.; Thompson, R. C.; Galloway, T. S.; Environ. Pollut. 2013, $178,483$.

79. Teuten, E. L.; Saquing, J. M.; Knappe, D. R. U.; Barlaz, M. A.; Jonsson, S.; Björn, A.; Rowland, S. J.; Thompson, R. C.; Galloway, T. S.; Yamashita, R.; Ochi, D.; Watanuki, Y.; Moore, C.; Viet, P. H.; Tana, T. S.; Prudente, M.; Boonyatumanond, R.; Zakaria, M. P.; Akkhavong, K.; Ogata, Y.; Hirai, H.; Iwasa, S.; Mizukawa, K.; Imamura, A.; Saha, M.; Takada, H. Transport and release of chemicals from plastics to the environment and to wildlife. Phil. Trans. R. Soc. B 2009, 364, 2027.

80. Ivar do Sul, J. A.; Costa, M. F.; Environ. Pollut., no prelo.

81. Barnes, D. K. A.; Nature 2002, 416, 808.

82. Ivar do Sul, J. A.; Barnes, D. K. A.; Costa, M. F.; Convey, P.; Costa, E. S.; Campos, L. S.; Oecol. Aust. 2011b, 15, 150.

83. Rubio, S.; Pérez-Bendito, D.; Anal. Chem. 2009, 81, 4601.

84. Bhandari, A.; Surampalli, R. Y.; Adams, C. D.; Champagne, P.; Kee Ong, S.; Tyagi, R. D.; Zhang, T.; American Society of Civil Engineers. 2009.

85. Lisboa, N. S. F.; Dissertação de Mestrado, Universidade Federal da Bahia, Brasil, 2012.

86. Lisboa, N. S; Fahning, C. S., Cotrim, G.; dos Anjos, J. P.; de Andrade, J. B.; Hatje, V.; da Rocha, G. O.; Talanta, no prelo.

87. Feitosa, R. S.; Sodré, F. F.; Maldaner, A. O.; Quim. Nova 2013, 36, 291.

88. European Monitoring Centre for Drugs and Drug Addiction - EMCDDA; Insights Series No 9. Assessing illicit drugs in wastewater Potential and limitations of a new monitoring approach Luxembourg. Office for
Official Publications of the European Communities: Belgium, 2008; Moção 61 de 2012, MMA-CNRH: Brasília, 2008.

89. Lacan, F.; Tachikawa, K.; Jeandel, C.; Chem. Geol. 2012, 300, 301.

90. Grenier, M.; Jeandel, C.; Lacan, F.; Vance, D.; Venchiarutti, C.; Cros, A.; Cravatte, S.; J. Geophys. Res. C: Oceans 2013, 118, 592.

91. Costa, M. F; Landing, W. M; Kehrig, H. A; Barletta, M; Holmes, C. D.; Barrocas, P. R.; Evers, D. C; Buck, D. G; Claudia Vasconcellos, A.; Hacon, S. S.; Moreira, J. C; Malm O.; Environ. Res. 2012, 119, 88;

92. Bisi, T. L.; Lepoint, G.; Azevedo, A. de F.; Dorneles, P. R.; Flach, L.; Das, K.; Ecological Indicators 2012, 18, 291.

93. Ducatti, C.; R. Bras. Zootec. 2007, 36, 1.

94. Faure, G.; Principles of Isotope Geology, $2^{\text {nd }}$ ed., John Wiley and Sons: New York, 1986.

95. Costa, M. F.; Liss, P. S.; Mar. Chem. 1999, 68, 87.

96. Costa, M. F.; Liss, P. S.; Sci. Total Environ. 2000, 261, 125.

97. Hatje, V.; Payne, T. E.; Hill, D. M.; McOrist, G.; Birch, G. F.; Zsymczak, R.; Environ. Int. 2003, 29, 619.

98. Payne, T. E; Hatje, V.; Itakura, T; McOrist, G. D.; Russell R.; J. Environ. Radioact. 2004, 76, 237.

99. Hood, M.; Broadgate, W.; Urban, E.; Gaffney, O.; Acidificação Oceânica. Sumário para formuladores de políticas públicas - Segundo Simpósio sobre oceanos em um mundo com elevado $\mathrm{CO}_{2}, 2009$.

100. Le Quéré, C., Andres, R. J.; Boden, T.; Conway, T.; Houghton, R. A.; House, J. I.; Marland, G.; Peters, G. P.; Werf, G. V. D.; Ahlström, A.; Andrew, R. M.; Bopp, L.; Canadell, J. G.; Ciais, P.; Doney, S. C.; Enright, C.; Friedlingstein, P.; Huntingford, C.; Jain, A. K.; Jourdain, C.; Kato, E.; Keeling, R. F.; Goldewijk, J.; Sitch, S.; Stocker, B. D.; Viovy, N.; Zaehle, S.; Zeng, N.; Earth Syst. Sci. Data 2013, 5, 165.

101. Feely, R. A.; Sabine, C. L.; Lee, K.; Berelson, W.; Kleypas, J.; Fabry, V. J.; Millero, F. J.; Science 2004, 305, 362.

102. Zeebe, R. E.; Annu. Rev. Earth Planet. Sci. 2012, 40, 141.

103. Kleypas, J. A. ; Buddemeier, R. W.; Archer, D.; Gattuso, J.-P.; Langdon, C.; Opdyke, B. N.; Science 1999, 284, 118.

104. Roberts, J. M.; Wheeler, A. J.; Freiwald, A.; Science 2006, 312, 543.

105. Amado Filho, G. M.; Moura, R. L.; Bastos, A. C.; Salgado, L. T.; Sumida, P. Y.; Guth, A. Z.; Francini-Filho, R. B.; Pereira-Filho, G. H.; Abrantes, D.P .; Brasileiro, P. S.; Bahia, R. G.; Leal, R. N.; Kaufman, L.; Kleypass, J.; Farina, M.; Thompson, F.; PloS One 2012, 7, e35171.

106. Doney, S. C.; Fabry, V. J.; Feely, R. A.; Kleypas, J. A.; Annu. Rev. Mar. Sci. 2009, 1, 169.

107. Orr, J. C. Em Ocean Acidification; Gattuso, J.-P.; Hansson, L., eds.; Oxford University Press: Oxford, 2011.

108. Gruber, N.; Phil. Trans. R. Soc. A 2011, 369, 1980.

109. Byrne, R.; Geochem. Trans. 2002, 3, 11.

110. Millero, F.; Woosley, R.; DiTrolio, B.; Waters, J.; Oceanography 2009, $22,72$.

111. Liu, X.; Millero, F. J.; Mar. Chem. 2002, 77, 43.

112. Martin, J. H.; Coale, K. H.; Johnson, K. S.; Fitzwater, S. E.; Gordon, R. M.; Tanner, S. J.; Hunter, C. N.; Elrod, V. A.; Nowicki, J. L.; Coley, T. L.; Barber, R. T.; Lindley, S.; Watson, A. J.; Scoy, K. V.; Law, C. S.; Liddicoat, M. I.; Ling, R.; Stanton, T.; Stockel, J.; Collins, C.; Anderson, A.; Bidigare, R.; Ondrusek, M.; Latasa, M.; Millero, F. J.; Lee, K.; Yao, W.; Zhang, J. Z.; Friederich, G.; Sakamoto, C.; Chavez, F.; Bick, K.; Kolber, Z.; Greene, R.; Falkiwski, P.; Chisholm, S. W.; Hoge, F.; Swift, R.; Tungel, J.; Turner, S.; Nightingale, P.; Hatton, A.; Liss, P.; Tindale, N. W.; Nature 1994, 371, 123.

113. Biller, D. V.; Bruland, K. W.; Mar. Chem. 2013, 155, 50.

114. Martin, J. H.; Fitzwater, S. E.; Gordon, R. M.; Global Biogeochem. Cycles 1990, 4, 5.

115. Buesseler, K. O.; Boyd, P. W.; Limnol. Oceanogr. 2009, 54, 1210.

116. Smetacek, V.; Klaas, C.; Strass, V. H.; Assmy, P.; Montresor, M.; Cisewski, B.; Savoye, N.; Webb, A.; D’Ovidio, F.; Arrieta, J. M.; Bathmann, U.; Bellerby, R.; Berg, G. M.; Croot, P.; Gonzalez, S.; 
Henjes, J.; Herndl, G. J.; Hoffmann, L. J.; Leach, H.; Losch, M.; Mills, M. M.; Neill, C.; Peeken, I.; Röttgers, R.; Sachs, O.; Sauter, E.; Schmidth, M. M.; Schwarz, J.; Terbrüggen, A.; Wolf-Gladrow, D.; Nature 2012, 487, 313.

117. Solomon, S.; Plattner, G.-K; Knutti, R.; Friedlingstein, P.; Proc. Natl. Acad. Sci. U.S.A. 2009, 106, 1704.

118. Archer, D; Eby, M; Brovkin, V; Ridgwell, A.; Cao, L.; Mikolajewicz, U.; Caldeira, K.; Matsumoto, K.; Munhoven, G.; Montenegro, A.; Tokos, K.; Annu. Rev. Earth Planet. Sci. 2009, 37, 117.

119. Johnson, K. S.; Berelson, W. M.; Boss, E. S.; Chase, Z.; Claustre, H.; Emerson, S. R.; Gruber, N.; Körtzinger, A.; Perry, M. J.; Riser, S. C.; Oceanography 2009, 22, 216.

120. Duarte, C. M; Hendriks, I. E.; Moore, T. S.; Olsen, Y. S.; Steckbauer, A.; Ramajo, L.; Carstensen, J.; Trotter, J. A.; McCulloch, M.; Estuaries Coasts 2013, 36, 221.

121. Martz, T. R.; Connery, J. G.; Johnson, K. S.; Limnol. Oceanogr. Meth. 2010, $8,172$.

122. Dickson, A.; Sabine, C. L.; Christian, J.R.; Guide to best practices for ocean $\mathrm{CO}_{2}$ measurements. PICES Special Publication 3, 2007.
123. Dickson, A. G. Em Guide to best practices for ocean acidification research and data reporting; Riebesell, U., Fabry, V. J.; Hansson, L.; Gattuso, J.-P., eds.; EPOCA - European Project on Ocean Acidification and Publications Office of the European Union, 2010, 17.

124. Kerr, R.; Cotrim da Cunha, L.; Souza, M. F. L.; Peretti A.; trabalho não publicado.

125. De la Cruz, N.; Giménez, J.; Esplugas, S.; Grandjean, D.; De Alencastro, L. F.; Pulgarín, C.; Water Res. 2012, 46, 1947.

126. Battaglin, W.; Drewes, J.; Bruce, B.; McHugh, M.; Water Resources IMPACT 2007, 9, 3.

127. Glassmeyer, S. T.; J. Am. Water Resour. Assoc. 2007, 9, 5.

128. Huerta-Fontela, M.; Galceran, M.T.; Martin-Alonso, J.; Ventura, F.; Sci. Total Environ. 2008, 397, 31

129. Vardakou, I.; Pistos, C.; Spiliopoulou, Ch.; Toxicol. Lett. 2011, 201, 191.

130. Gurr, C. J.; Reinhard, M.; Environ. Sci. Technol. 2006, 40, 2872.

131. Jardim, W. F.; Pure Appl. Chem. 1998, 70, 2259.

132. Suib, S.; Front. Chem. 2013, $1,1$.

133. http://cdiac.ornl.gov/oceans/glodap/, acessada em Julho 2013

134. http://odv.awi.de, acessada em Julho 2013. 